\title{
Why Continuous Improvement Programs Fail in the Egyptian Manufacturing Organizations? A Research Study of the Evidence
}

\author{
Mohammed Hamed Ahmed Soliman \\ Engineering and Science Services, School of Continuing Education, The American University in Cairo, Egypt \\ Email:mohammed@personal-lean.org,m.h.ahmed@ess.aucegypt.edu
}

How to cite this paper: Soliman, M.H.A. (2017) Why Continuous Improvement Programs Fail in the Egyptian Manufacturing Organizations? A Research Study of the Evidence. American Journal of Industrial and Business Management, 7, 202-222. https://doi.org/10.4236/ajibm.2017.73016

Received: February 6, 2017

Accepted: March 26, 2017

Published: March 29, 2017

Copyright $\odot 2017$ by author and Scientific Research Publishing Inc. This work is licensed under the Creative Commons Attribution International License (CC BY 4.0). http://creativecommons.org/licenses/by/4.0/

\section{Open Access}

\begin{abstract}
The purpose of this paper is to present the core variables derived from literature that contributes to the failure of continuous improvement (CI) programs in the Egyptian manufacturing industry. The approach used is to find the previous literature reviews of the problem, group the variables affecting the problem, develop the research model and theoretical frameworks, and test the variables through a survey using the appropriate scale and measurements. From the data measurements and analysis, continuous improvement programs can fail due to multi factors; they can be grouped under six themes: strategic planning, change management, knowledge management, performance measurement, CI performance \& sustainability, and motivation. The research is limited to the manufacturing industry. Continuous improvement programs/initiatives defined for the purpose of the study as TQM, Lean, Six Sigma, and Plan-DoCheck-Act (PDCA) cycle. The value of this research is to create awareness for the manufacturing organizations about the requirements of change in the form of CI implementation.
\end{abstract}

\section{Keywords}

Continuous Improvement, Lean Manufacturing, Industrial Management, Lean Leadership, Improvement Sustainability

\section{Introduction}

Many companies aren't achieving the desired outcomes from the continuous improvement programs. The continuous improvement initiatives are failing to sustain, affecting the organizations performance. About $80 \%$ of continuous improvement projects fail [1] [2] [3] [4] as companies try to use continuous improvement methodologies like a toolkit, copying and pasting the techniques without trying 
to adapt the employee's culture, manage the improvement process, sustain the results, and develop their leaders.

\section{Preliminary Data Collection}

Data has been collected about the company's history, management behavior, employee's culture and attitudes through direct observation, several visits and interviews.

\subsection{Company Background}

An Egyptian crystal manufacturing company produces crystal pieces under its own name. The company produces clear and colored crystals for diverse uses including lighting, accessories, fashion pieces, chandeliers, figurines and special projects. It was considered the world's largest manufacturer and exporter of crystal, having a production capacity that exceeds 100 tons of crystal per day and exporting to more than 50 countries across the globe.

The company established in Cairo, Egypt and began with a 2200 square meter workspace that employed 200 craftsmen and utilized simple, basic production tools. Nowadays, the company had expanded into 5 crystal factories that cover a total build-up area of more than 1.2 million square meters. The factories employ more than 28,000 craftsmen and women, and the company still stands at that status till today.

As the company expanded, the need for custom-made tools and machinery resulted in the company's adoption of a backward integration strategy where these tools and machines were designed, developed and manufactured by the company for itself.

In 2000, the company launched the Crystal Fashion Components division, producing clear and colored crystals for the fashion industry with all its sectors, including accessories, apparel, jewellery and decoration.

\subsection{Management Philosophy and Organizational Structure}

The company's organizational structure is a classic functional structure; it has 5 main divisions/sectors: financial, engineering \& design, production, research and development $(R \& D)$, and industrial engineering. It has narrow span of control so each manager was responsible for few number of people to improve communication in each department. The management approach is management by objectives (MBO) where each employee is assigned a set of tasks to do and they are being asked to introduce the results quarterly. The rewarding system and the bonus are based on the results achieved by each individual. After doing several interviews it was obvious that targets assigned to employees are divisional targets which aren't fully aligned with the company philosophy, values and the long-term business objectives. Each department is working to its own set of purposes and goals.

Senior managers and directors are relying on monthly reported metrics and seem not personally engaged in the problems solving process; they aren't fully 
aware of many of the operational problems.

There is a lack of top management commitment to the continuous improvement of the system and the product to improve operational factors: quality, productivity, and inventory turns. There is no system to discuss customer complaints to improve product quality, safety and reliability.

The R \& D department was created to improve quality with no efficient communication and cooperation with the other teams working in the production to improve process.

\subsection{Attitudes and Behavioral Responses}

The company is operating using the management by objectives. The system reward individuals and thus don't encourage teamwork. There are no incentives based on team accomplishments and overall performance. There is a system to encourage new ideas, but no real improvement or implementation of these ideas in real work.

Although employees and workers are very skilled in their technical areas and well-trained, but the company don't have an effective training system to train their employees on how to accomplish targets and achieve the business goals within the organizational values and behavior. There is no alignment between the divisional targets and the overall company's business goals.

There is a high level of labors and employee's turnover, workers quite because they aren't involved in improving their work, their voices aren't heard plus the working environment is tough and not healthy. This doesn't support building royal employees that are willing to improve their work and the system.

\section{Literature Review}

When looking at the continuous improvement (CI) initiatives failure and the global statistical around the world, we figure many companies are complaining that continuous improvement programs using lean, TQM, six sigma or PDCA cycle didn't achieve their long-term goals, and the improvement impact was very shortlived. Reports that most organizational change efforts fail or do not meet targets [5] demonstrate the need to identify and address the issues associated with organizational change. Specifically, in relation to continuous improvement, Angel and Pritchard [2] state that 60 per cent of Six Sigma initiatives fail to achieve the desired results.

Liker [4] stated 7 out of each 10 lean projects fail as companies try to use lean like a toolkit, copying and pasting the techniques without trying to adapt the employee's culture, manage the improvement process, sustain the results, and develop their leaders. As an example, when the Toyota production system was created, the main goal was to remove wastes from the shop floor using some lean techniques and tools. What was not clear is that this required from Toyota a long process of leadership development, and a high commitment to training and coaching their employee. A Failure to achieve and sustain the improvement is a problem of both management and leadership as well as the improper understanding 
of the human behavior, and the required culture to success [1].

Liker and Convis [6] stated organizations that are trying to improve their businesses using lean initiatives without a shared vision or clear purposes that align people, plans, methods, and efforts with strategies to achieve their business objectives aren't highly successful organizations.

Ahmed [1] summarized the reasons of why companies failed to achieve and sustain the results using the continuous improvement methodologies as follow: 1) Management style, he defined the gap between industrial management and traditional management; 2) Top management commitment; 3) The motivational behavior; 4) The misuse of the tools and techniques which is a result from lack of training and the absence of continuous improvement culture; 5) Management decisions are based on short-term financial thinking.

Jaca et al. [7] summarized the suitability factors of CI as follow: 1) Management commitment and buy-in; 2) The use of performance indicators and measurements; 3) Linking the CI objectives to the strategic vision and goals; 4) Workforce involvement; 5) Training; 6) Teamwork promotion; 7) Selection of the appropriate area for improvement; 8) Motivation.

Soliman [8] presented the management behaviors and attitudes as an important factor in achieving and sustaining the CI performance results. Motivation, core organizational, values, leadership development, culture change are the real factors of any business success.

According to many literature reviews, surveys and interviews, factors that can contribute in the success of continuous improvement programs are.

\subsection{Management Behaviors and Attitudes}

Soliman [9] and Ahmed [1] described the distinction between the Japanese approach of achieving the strategic direction (hoshinkanri) and management by objectives (MBO). For decades, management has relied on the old principle of management by objectives (MBO) - also called management by results (MBR). This is a short-term method and not a philosophy. Drucker [10] invented the theory, and it is still being taught in many business schools. The principle focuses only on the results and numbers and rewards the winners. This means businesses don't care how their employees do things-so long as they get the numbers. They might lay off people, ignore employee trainings, lose the trust of their employees, break the law, ignore team orientations, or produce unsustainable processes to get the numbers quickly. As long as they get the numbers, though, they are fine. Those who succeed get rewarded, and those who fail are punished. This makes people hide their problems and resist change. It creates a very bad culture that leads to bad results. Still, though, many companies think $\mathrm{MBO}$ as a tool is not a problem, but what is $\mathrm{MBO}$ as a tool? It is managers making decisions about what they believe the business needs and turning those decisions into objectives for their people. Sometimes objectives are discussed among groups of people, but often they are handed down from the top. Since the focus is only on the results, there are many lost opportunities [11]. 
$\mathrm{MBO}$ and other traditional management habits focus on managing people based on command and control [6]. This is management through systems. Managers have learned to manage processes from a distance. They work from their offices with no direct involvement in those processes. They have lost their connection to reality. As a manager, it is your job to manage people. However, many managers make employees do their jobs and apply systems instead of empowering, developing, and motivating those employees. Managers should get employees to agree about problems and seek solutions by themselves or with the help and support of the managers to remove roadblocks and encourage new ideas. In MBO systems, managers tend to use metrics to evaluate people and control them. Metrics should be used to evaluate progress and guide employees in the right direction [1]. People should have a degree of autonomy and feel they are contributing through the success of their work rather than being used to achieve process results.

A well management system using hoshinkanri, however, focuses on peoplenot the process. It details how people can be developed to solve their own problems [6] [8]. Table 1 shows the different between management by objectives as a method for planning and control and hoshinkanri as a philosophy for achieving the strategic direction.

"Management is about teaching and improving" [12] [13]. Managing people to get sustainable results requires strong leadership. People are naturally resistant to change. It is very difficult to get them to change their behaviors. Plus, many people still view improvement methodologies such as lean as tools for cutting resources. Therefore, people are fearful about losing their jobs as a result of process-improvement efforts. One of the most common problems leaders face

Table 1. Comparison between MBO and HoshinKanri.

\begin{tabular}{|c|c|}
\hline $\mathrm{MBO}$ & $\begin{array}{l}\text { Industrial Management using hoshinkanri for direction planning and } \\
\text { deployment }\end{array}$ \\
\hline $\begin{array}{l}\text { Invented by Peter Drucker } \\
1954\end{array}$ & $\begin{array}{c}\text { Originated in Japan in } 1961 \text { and used successfully by Toyota and } \\
\text { top-tier companies in US and Japan }\end{array}$ \\
\hline $\begin{array}{l}\text { Management based on } \\
\text { command and control }\end{array}$ & $\begin{array}{c}\text { Management is based on empowering, motivating, and developing } \\
\text { people on problems solving skills }\end{array}$ \\
\hline Focus on the & $\begin{array}{c}\text { Focus on the process not the results this include the plan, the } \\
\text { method, the innovation, and people development \& training on } \\
\text { problems solving }\end{array}$ \\
\hline Recognize individuals & $\begin{array}{l}\text { Rewarding system is based on teamwork, overall performance and } \\
\text { accomplishments }\end{array}$ \\
\hline Promote individualism & Promote teamwork \\
\hline Top-down method & Top-down with linkage to shop floor \\
\hline $\begin{array}{l}\text { Managing process via distance } \\
\text { and rely on reported metrics }\end{array}$ & $\begin{array}{l}\text { Managing on shop floor (gemba principle) and base management } \\
\text { decisions on facts }\end{array}$ \\
\hline $\begin{array}{l}\text { Use metrics to evaluate people } \\
\text { and results }\end{array}$ & $\begin{array}{l}\text { Give people degree of autonomy and use metrics to monitor the } \\
\text { work progress and understand the obstacles need to be removed to } \\
\text { improve the process }\end{array}$ \\
\hline
\end{tabular}

Focus on the strategic thinking Link the strategic thinking to shop floor, use gemba as a management only principle, and use visualization, standardization to improve the work 
when implementing lean is getting buy-in from the top senior managers and getting the bottom workers involved [13]. Bottom workers need to feel they are protected and that lean won't make them lose their jobs. Layoffs must be separated from the continuous improvement.

A good strategy should involve managers in the details and they should use the management technique of gemba "go and see" [6]. Simultaneously, they should focus on strategic thinking and the true north. This is unlike MBO, which focuses only on strategic thinking and doesn't link this to shop floor efforts [11]. There is a lost connection between shop floor efforts and strategic business objectives. This connection is very important, though, to get everyone in the company to contribute to achieving business results.

\subsection{Linking the Strategic Thinking to the CI Efforts}

Liker and Convis [6] presented how the poor linkage between the strategic thinking and the shop floor effort affect the achievement and sustainability of continuous improvement.

In bureaucratic management there is poor linkage between the shop floor's efforts and the organization's goals. Every department is working toward its own objectives.

"Linking strategic deployment to the shop floor is one of the ultimate lean goals. The point of having a vision and clear targets is to keep your people focused on clear things, and sooner or later, you will gain their trust, and everything will be easier" [11] [13].

You have to be clear about what you want to achieve. Reducing scrap by 10 percent is a target, but how might this reflect your business needs and current situation?

Spending too much time on the shop floor won't get it done. You have to link your strategic deployment to the shop floor. This is Toyota's ultimate strength [13]. You have to link your work and translate your efforts to achieve the goals that reflect the current business needs. This will help ensure long-term business survival and improvement.

Efforts should reflect something that serves the business's needs. This could include doing a lot of kaizen to improve productivity, standardize the work, and reduce quality defects. What needs to be done to improve the business right now? If a business wants to improve cash flow, look to reduce inventory and improve turns. Make cells, manufacture parts in single-piece flow, move to a pull system, level the product mix, and speed up the changeover [9]. This can reduce batch sizes and improve cash flow. With daily management support, it can also achieve a greater focus on people development. Establishing a clear direction and making sure the efforts are concentrated on high-payoff problems will yield results. Evaluation parameters must be used to establish a link between budget indicators and problem solving [13].

To be one of the leading suppliers in your industry, you need to get new customers. You have to prove your product is superior in quality. To improve qual- 
ity, you have to improve the process on the shop floor. To reduce defects and improve quality for your customers, you need the jidoka approach, and you need to prevent bad parts from passing to the next process [8]. Machines have to be designed to recognize the bad parts-just as people have to be trained to do so. Then the proper management procedures must be in place to ensure defects are detected and removed [4].

Establish metrics for shop floor efforts and use visual boards to present the targets. This way, people can work to achieve the targets and solve problems. They will be able to see how these targets are tied to the bigger stream and the business objectives [13].

\subsection{Promoting Teamwork and Creativity through Motivation and Support}

While management's main role is to teach and improve, management must also support, listen, motivate, empower, and challenge. If you want people to do what you need them to do and do it well and with passion, you have to find the key to motivate and inspire them.

Liker [6] presented the motivation as part of the continuous improvement system. Taylor's model is predominant in the classic management approach. Taylor [14] said, "If each employee's compensation was linked to his or her output, his or her productivity would go up" [14].

Put another way, happier employees are more productive. An employee should be paid enough to provide a decent standard of living (This varies from one person to another). Financial benefits and other motivators should be adapted and paid wisely.

In 1975, Arthur Friedman (a business entrepreneur in the United States) allowed his employees to set their own wages. Friedman's experiment worked. The organization was profitable, employees didn't quit, they didn't steal, and they were rarely absent.

There is a growing body of evidence that direct incentives often undermine performance, motivation, and job satisfaction. Unfortunately, the search for the magic stimulus continues in some business school classrooms to this day [15].

Liker and Convis [6] stated, "Psychological experiments show that paying people to do something that they already want to do either because they enjoy it or because they want to get good at it can kill the intrinsic motivation. The company will have to continually provide rewards if it wants to continue to see good behavior".

While Taylor's approach focuses on individual incentives based on productivity, Toyota focuses on teamwork, and evaluations are based on group performance [6].

According to many psychologists, incentives based on individual accomplishment can discourage teamwork. Remember, no teamwork means no problem solving. Incentives, therefore, should be tied to teamwork, large accomplishments, and overall performance. 
What would happen if an improvement project was tied to metrics and the company had to reduce its benefits value due to a financial statement? Would employees still be working with the same productivity? According to Taylor, because the employees' compensations are linked to output, when compensation is decreased, output would also decrease.

As Liker and Convis [6] emphasize, the Japanese branch of Toyota tries to avoid tying specific rewards to specific metrics. They fear employees will focus narrowly on what is measured and ignore the other parts of the job.

\subsection{Aligning the Company's Vision, Mission, Values and the Goals}

Soliman [9] discussed how developing a strategy mission, vision, and values and align the goals is important for organizations seeking high performance results with continuous improvement methodologies.

If the company has clear strategic goals that are broken down into achievable metrics, employees will be able to generate ideas and explain how their ideas are aligned with these goals. The system itself will drive motivation and creativity. There will be no more need for financial motivators that undermine performance and kill motivation [8] [15]. A system that trains supervisors and engineers to listen to the workers' problems and allows information to be shared between groups can be exceptionally motivational.

Any company needs a vision and clear purpose to help people see not just their own improvements but how those improvements tie in to the bigger stream [13]. People need a clear direction. They need to know where you're taking them.

Traditionally, your vision should be over five years, and your vision statement should be generic enough that it will fit any future acquisitions. Think of your vision in business terms. This could include number-one market share, zero warranty cost, or 100 percent accountability [3].

Break it down into stretch goals for your employees and departments to use [9]. Make sure these stretch goals are concrete and aligned with your strategic business objectives by aligning them with the value you provide to your customers [3].

Concrete stretch goals aligned with organizational strategies are the key to making improvement a priority. Stretch goals break down strategic goals into easy-to-understand bites that workers can digest. They are a main way to cascade organizational values down from above to the front lines. For example, it means nothing to your employees that the goal is to be the leading industry supplier or having no.1 market share. However, breaking that aims into stretch goals yields metrics. This could be a 50 percent reduction in defects per year or 20 percent productivity gain each year. Those have measurable results [9].

One of the most fundamental mistakes many companies make is trying to improve something without a clear strategy that serves customer requirements and the success of the business.

\subsection{Training and Developing a Culture of Continuous Improvement}

Rother [16] described the Japanese method of training and developing a culture 
of continuous improvement in Toyota.

Classically, companies that want to train their employees tend to ask them what skills they need or lack. This determines what to train them on. The training is then delegated to the training department or human resources. That department assesses the employees' previous knowledge and performances and trains them accordingly. What about the skills these employees don't have, though? [16].

Taking Toyota as an example, while many companies still rely on formal educational programs to train employees, Toyota uses a completely different pattern of learning. Most companies still think of training as teaching people how to solve problems, but Toyota teaches people how to develop solutions for problems. Toyota teaches a routine of thinking and acting that harnesses the human capability to improve and solve problems. Toyota doesn't teach its employees tools and techniques. In fact, Toyota's production system doesn't offer solutions-just the means to develop solutions [16].

Toyota inserted continuous improvement into its employee DNA by using a different routine [16]. Employees were coached on how to solve problems. Improvement became a part of each employee's daily routine-something that can't be achieved through formal training or classrooms. The learning routine through the PDCA cycle was a good example.

As a commitment to self-education and continuous development, Toyota uses a different approach. Its coaching system continuously develops people and ensures each mentee has a mentor. For example, the team leader coaches the team member, and the group leader coaches the team leader [1]. This is Toyota's method for passing its improvement behavior on to all organization members [16].

Apart from the fact that most companies don't have real systems to coach their employees on how to achieve the business's competitive targets and accomplish the process results within the organization's strategies and values [1] [9], some companies do seek to continuously develop their employees and provide positive environments for learning. For example, these companies have libraries so employees can read. They encourage people to learn and produce new ideas within highly motivational systems. This is a good start, but if improvement is not embedded in the organization's daily routine, it won't be everyone's priority to learn and act.

Continuous coaching at the workplace using the Toyota Way builds strong leaders. Within that system, people are mentored on how to improve a process toward a target. Embedding this into the organization's daily routine will make improvement everyone's habit. This is a main reason why continuous improvement has become a pattern for everyone in Toyota's organization. The learning cycles Toyota leaders have to take, the continuous coaching at the workplace, and the utilization of problems as opportunities to learn and grow have made Toyota a remarkable company.

Toyota doesn't rely on certifications and formal education programs. In fact, Japanese business culture doesn't think much of such certifications or MBAs. Instead, these businesses believe management and leaders should be taught at the 
gemba-where the actual work is done. This is where Toyota and many other Japanese businesses conduct most of their trainings [6] [16].

\section{Research Problem Definition}

The Egyptian manufacturing organization was trying to improve the process without looking at the real operational issues and the management system. The strategic planning process wasn't adequate. There is no proper link between the continuous improvement efforts and the strategic business goals. Employees aren't focusing on what's matter; there is no management system to improve focus, linkage, accountability, buy-in, communication, and involvement in a corporation in order to continuously improve the product. There is no culture of continuous improvement to sustain the results.

\section{Research Objectives}

- Align the business goals with the continuous improvement of the process to achieve the CI targets of productivity, quality and costs.

- Determine business needs, and align business goals with the divisional targets.

- Improve management buy-ins, communication, and involvement in cooperation and develop future leaders.

- Improve employees training to embed the culture of continuous improvement throughout the organization.

- Improve motivation and creativity.

\section{Research Questions}

- What do we need to do to continuously improve the process?

- How to align the vision and business goals with the continuous improvement efforts?

- How do we change the employee's culture to improve the process?

- What is the best training method to change culture and embed the continuous improvement throughout the organization and with everyone in the company? Can we make the continuous improvement embedded in everyone's daily routine?

\section{Theoretical Frameworks}

In order for a company to achieve the continuous improvement goals and improve the process it has to improve the strategic planning process, being adaptable to change, in cooperate the performance measurements and indicators, improve training, continuously monitor and measure the sustainability of the results, and improve motivation and creativity. The dependent variable here is the achievement and sustainment of continuous improvement which managers are interested to focus in. The independent variables are the strategic planning, change management, knowledge management (related to training), performance measurements, continuous improvement suitability, and motivation. Those in- 
dependent variables highly affect the achievement and sustainability of continuous improvement outcomes. Figure 1 represents the hypotheses model and the suggested frameworks.

From the previous figure we conclude:

$\mathrm{H} 1$ : If the strategic planning process is improved and CI goals are in cooperated, then the company can achieve the continuous improvement outcomes and sustain the results.

H2: If the company is adopted to change, the company can achieve and sustain the continuous improvement results.

H3: The more we in cooperate the appropriate measurements into the process, the more the organization can monitor its performance and progress and the less likely processes will slip back.

H4: If the organization provide the continuous improvement knowledge and training to its employees, their skills will improve and they will be able to manage their work with the new methods and techniques and this will improve the sustainability of the process.

H5: If the company is analyzing the performance of CI sustainability by collection data in longitudinal format, then the company can insure the results are sustained.

H6: Employee motivation affect the achievement and sustainability of the

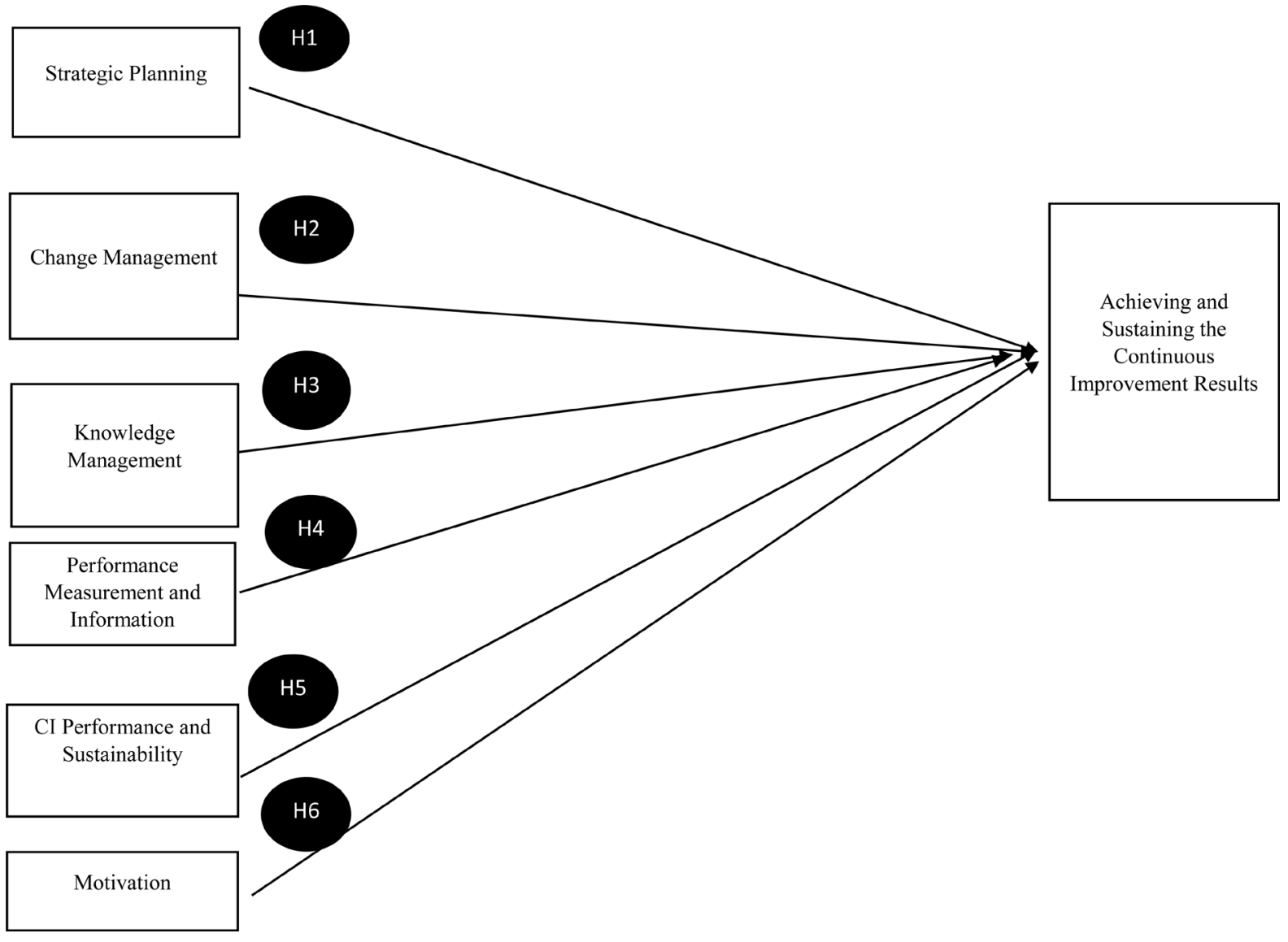

Figure 1. Theoretical framework's and hypotheses development. 
continuous improvement results.

\section{Research Design}

- Purpose of research: Hypothesis testing.

- Type of Investigation: Casual study to determine the cause and effect in an artificial environment.

- Extend of Researcher Interference with the Study: High interference as the study will strongly affect the working routine.

- Study Setting: Contrived setting as the study is casual and being done in an artificial environment.

- Unit of Analysis: Individuals.

- Time Horizon: Longitudinal studies as measurements will be taken before and after to determine if the process has been improved.

\section{Measuring the Variables}

\subsection{Strategic Planning (H1)}

The Scale and Reliability

The Measuring elements of the variable strategic planning according to [17] are stated in Table 2 . A five-point Likert scale $(1=$ strongly disagree to $5=$ strongly agree) was used to capture the level of agreement of each respondent on each item. The questionnaire had a total of 17 items ( 1 to 17 in Table 2). The Likert scale was used to provide a consistent response format for further statistical analysis [18]. The five point Likert scale was chosen over the seven point Likert scale to reduce the respondent burden, and also because the seven-point scale does not increase reliability [19].

Table 2. Strategic planning structure \& cronbach alpha value.

\begin{tabular}{|c|c|c|}
\hline Cronbach $\alpha$ value & Variable & Elements of Variable \\
\hline 0.95 & $\begin{array}{c}\text { H1-Strategic } \\
\text { Planning }\end{array}$ & $\begin{array}{l}\text { 1. CI as an element of the vision and mission } \\
\text { 2. CI goals are understood at every level of the organization } \\
\text { 3. Effective communication of reached goal } \\
\text { 4. Alignment of CI and departmental goals } \\
\text { 5. CI as strategic plan to meet customer needs } \\
\text { 6. Perception of CI as a working value } \\
\text { 7. Improvement as core element for company's permanence } \\
\text { 8. Communication of CI goals } \\
\text { 9. Use of historical data to develop CI goals } \\
\text { 10. Role models in CI initiatives presented by managers } \\
\text { 11. CI goals drive day-to-day work } \\
\text { 12. Systematic follow-up of CI goals } \\
\text { 13. Frequent monitoring of CI goals } \\
\text { 14. CI-goal adjustments based on follow-up } \\
\text { 15. Accessibility to CI leader } \\
\text { 16. Accurate organizational structure to support CI } \\
\text { 17. Available resources across the firm to support CI }\end{array}$ \\
\hline
\end{tabular}




\subsection{Change Management ( $\mathrm{H} 2)$}

The Scale and Reliability

The Measuring elements of the variable change management according to [17] are stated in Table 3 . A five-point Likert scale $(1=$ strongly disagree to $5=$ strongly agree) was used to capture the level of agreement of each respondent on each item. The questionnaire had a total of 14 items (1 to 14 in Table 3 ). The Likert scale was used to provide a consistent response format for further statistical analysis [18]. The five point Likert scale was chosen over the seven point Likert scale to reduce the respondent burden, and also because the seven-point scale does not increase reliability [19].

\subsection{Knowledge Management (H3)}

The Scale and Reliability

Figure 2 shows the dimensions of the variable knowledge management. The measuring elements of the variable knowledge management according to Sengh and Gupta [20] are stated in Table 4 consist of 27 items total. According to Sengh and Gupta [20], a five-point rating scale ranging from 1 "strongly disagree" to 5 "strongly agree" has been used. Alpha reliability of this scale is 0.939 [20].

Table 3. Change management structure \& cronbach alpha value.

\begin{tabular}{ll}
\hline Cronbach $\alpha$ value $\quad$ Variable & \multicolumn{1}{c}{ Elements } \\
\hline & 1. Openness to suggestion of ideas \\
& 2. CI empowers employees \\
& 3. Employees' contribution to meet customer needs \\
& 4. Recognition of innovation and creativity \\
& 5. Organization learns from CI experiences \\
& 6. Active role of manager in the CI process \\
V2-Change & 7. Risk-taking to promote innovation and creativity \\
Management & 8. Failure as a learning opportunity \\
& 9. Evolving working environment \\
& 10. Mindful responses rather than inefficient solutions \\
& 11. Change adoption is supported by success stories \\
& 12. Dynamic portfolio of lessons learned \\
& 13. Overall support of the organization for adopting change \\
& 14. Leaders act as CI role models by embracing change
\end{tabular}

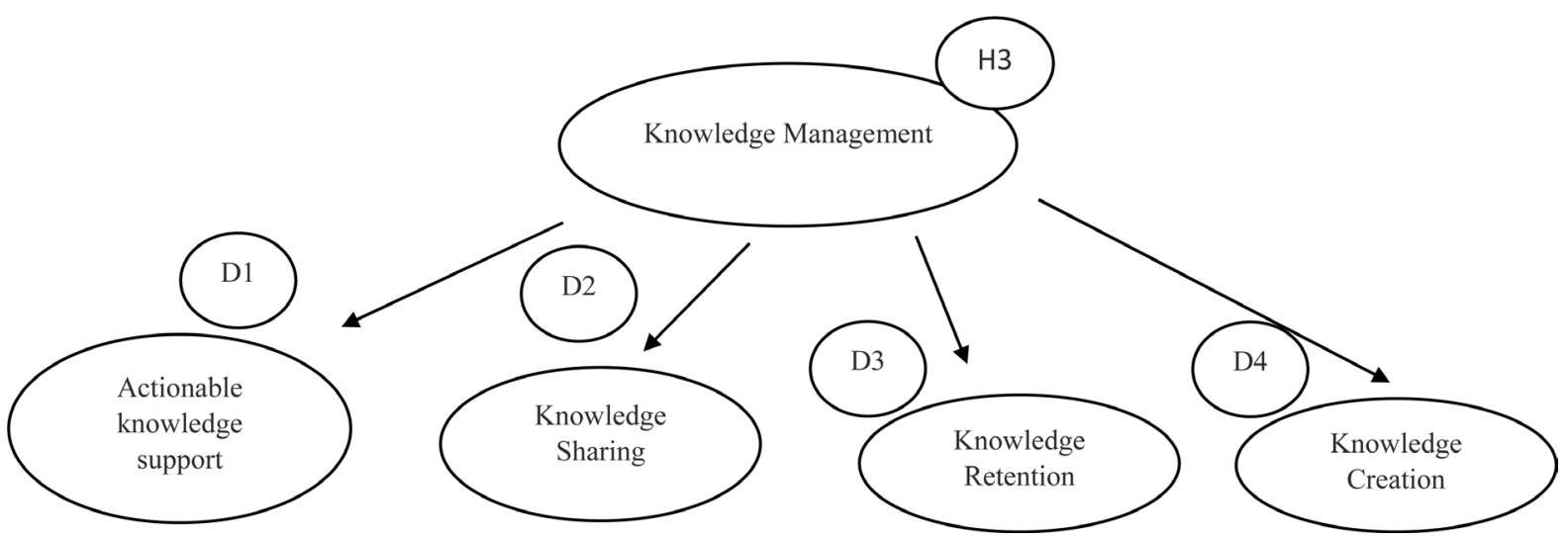

Figure 2. Knowledge management variable and its dimensions. 


\subsection{Performance Measurement (H4)}

The Scale and Reliability

A five-point Likert scale ( $1=$ strongly disagree to $5=$ strongly agree) was used to capture the level of agreement of each respondent on each item. The questionnaire had a total of 5 items ( 1 to 5 in Table 5 ). The Likert scale was used to provide a consistent response format for further statistical analysis [18]. The five point Likert scale was chosen over the seven point Likert scale to reduce the respondent burden, and also because the seven-point scale does not increase reliability [19].

\subsection{Sustainability (H5)}

The Scale and Reliability

Table 4. Knowledge management structure \& cronbach alpha value.

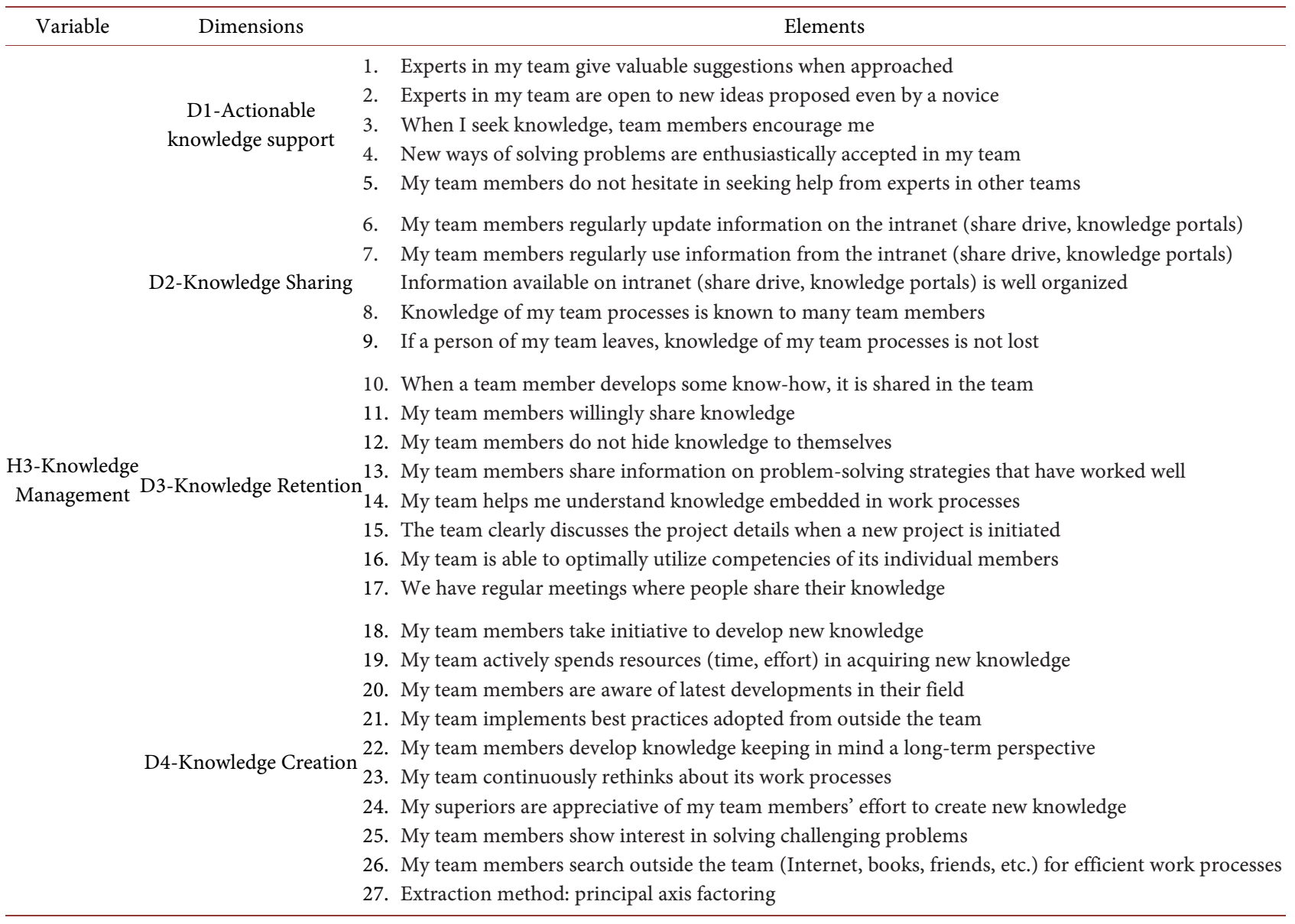

Table 5. Performance measurements structure \& cronbach alpha value.

\begin{tabular}{|c|c|c|}
\hline Cronbach $\alpha$ value & Variable & Element \\
\hline \multirow{5}{*}{0.90} & \multirow{5}{*}{ H4-Performance Measurements } & 1. Consistent overall and departmental goals \\
\hline & & 2. Display of CI metrics \\
\hline & & 3. CI metrics at operational level \\
\hline & & 4. CI goals reflect customer requirements \\
\hline & & 5. Longitudinal collection of CI metrics \\
\hline
\end{tabular}


The Measuring elements of the variable CI sustainability according to [17] are stated in Table 6 . A five-point Likert scale $(1=$ strongly disagree to $5=$ strongly agree) was used to capture the level of agreement of each respondent on each item. The questionnaire had a total of 3 items ( 1 to 3 in Table 6 ). The Likert scale was used to provide a consistent response format for further statistical analysis [18]. The five point Likert scale was chosen over the seven point Likert scale to reduce the respondent burden, and also because the seven-point scale does not increase reliability [19].

\subsection{Motivation (H6)}

Table 7 represents two types of motivators. According to Manolopoulos [21] the motivators were mainly identified in the classical study conducted by Herzberg [22], which was revalidated in the work of Jurgensen [23]. Herzberg [22] identified: firstly, intrinsic factors in employee motivation, such as achievement, recognition for achievement, the work itself, responsibility, growth and advancement; and secondly, extrinsic factors, such as company policy and appreciation, supervision, interpersonal relationships, working conditions, status, payment and security.

The Scale and Reliability

The measuring elements of the extrinsic and intrinsic motivators are represented in Table 8. A five-point Likert-type scale was prepared, where the scale value " 5 " indicates a strong prevalence of the motivator and scale value " 1 " a weak presence. The reliability coefficient $\alpha$ is 0.71 for extrinsic and 0.74 for intrinsic motivators respectively. Thus, the reliability coefficients were above 0.55 , which is considered the cutoff point of basic research [24] and higher to 0.70 which is the suggested reliability level proposed by Nunnally [25].

\section{Sample \& Demographics}

Because the study required data to be collected in a longitudinal format in order

Table 6. CI suitability structure \& cronbach alpha value.

\begin{tabular}{|c|c|c|}
\hline Cronbach $\alpha$ value & Variable & Element \\
\hline 0.84 & $\begin{array}{c}\text { H5-CI } \\
\text { Sustainability }\end{array}$ & $\begin{array}{l}\text { 1. Defined metric for ongoing CI training in the long term } \\
\text { 2. Defined metrics for waste reduction in the long term } \\
\text { 3. CI initiatives are defined metrics }\end{array}$ \\
\hline
\end{tabular}

Table 7. Motivators classification.

\begin{tabular}{|c|c|}
\hline \multicolumn{2}{|c|}{ Motivators } \\
\hline $\begin{array}{l}\text { Extrinsic Motivators } \\
\text { - } \quad \text { Provision of fair wages } \\
\text { - } \quad \text { Provision of pay incentives } \\
\text { - } \quad \text { Communication and cooperation in the } \\
\text { - } \text { Oporking environment } \\
\text { - } \quad \text { Security in the workplace } \\
\text { - } \quad \text { Working condition }\end{array}$ & $\begin{array}{l}\text { Intrinsic Motivators } \\
\text { - } \text { Opportunities to advance the field of } \\
\text { employee's expertise } \\
\text { - } \quad \text { Need for creative work } \\
\text { - } \quad \text { Need for esteem and reputation } \\
\text { - } \\
\text { - } \\
\text { Need for competence }\end{array}$ \\
\hline
\end{tabular}


Table 8. Motivation structure.

\begin{tabular}{ll}
\hline Motivators & Survey Questions \\
\hline
\end{tabular}

1. Provision of fair wages

2. Provision of pay incentives

3. Communication and cooperation in the working environment

4. Opportunities for hierarchal advancement

5. Security in the workplace

6. Working condition

7. Opportunities to advance the field of employee's expertise

8. Need for creative work

9. Need for esteem and reputation

10. Recognition for work

11. Need for competence

12. Opportunities to take responsibilities
In relation to the effort I devote to my work, my position, my prior working experience and educational background, the relevant wages in the private sector and the economic situation of the country, I consider to have a fair wage

Our organization has introduced performance related pay schemes

The management makes any possible effort to create a collaborative work environment, to build relationships of trust and mutual understanding among employees, to rely on open and honest communication and to share knowledge and information in all directions

The organization has set clear criteria for promotions, based on meritocracy and transparent procedures

The norm in our organization is that employment is Protected

The management cares about the health and safety of employees. It provides adequate and up to date IT support and infrastructure. It respects the individual characteristics of employees' personality and encourages their development

Your employment requires different specialized skills and you obtain ongoing feedback indicating success in their accomplishment

My job is creating and producing something meaningful

Your employment provides you the opportunity to "make a difference" to society

Work evaluation is based on explicit performance criteria. Performance evaluation forms include the roles and responsibilities of employees, the extent of achievement to pre-determined targets and the quality of final deliverables. Evaluations are fair and constructive. Good evaluation has a positive impact on career advancement and/or pay raise of employees

The organization encourages the participation of employees in seminars, workshops and Conferences

The organization provides employees the freedom in deciding how to carry out their work and encourages them to take initiatives

to analyze the performance and sustainability of the Continuous Improvement of the process, questionnaires were applied several times (repeated observations) to the company about every 2 months starting from AUG 2015 through March 2016. Questionnaires were handled directly by the Human Resources Manager or the CI Coordinator, who selected the respondents.

The company consists of 2000 employees working in several functional depts. But only a single plant where CI is implemented was considered for the survey. Total no of employees in this plant were 75 employees. The questioners were applied to 63 respondents. The functional area where respondents were working at the time they answered the questionnaire, $43.65 \%$ of respondents were employed in the manufacturing/production. The second most common functional area was customer service, which accounted for $24.1 \%$ of the respondents.

The respondents were categorized by the level of their job position: team members who worked at the operational level (52 members), and managers who had a supervisory or senior role (11 managers).

\section{Analysis of Results}

In the statistical analysis of the hypotheses, participants were divided into two groups (Managers/supervisors and Team members) in order to see how these principles are perceived from the different points of view.

Table 9 represents the mean of the answers obtained from the questions and 
Table 9. Statistical analysis of variables.

\begin{tabular}{ccc}
\hline Hypothesis & Managers & Team Members \\
\hline Strategic Planning (H1) & 3.5 & 2.76 \\
Change Management (H2) & 2.2 & 2 \\
Knowledge Management (H3) & 3.1 & 2.61 \\
CI Performance Measurements (H4) & 3.47 & 3.5 \\
CI Sustainability (H5) & 1.66 & 1.83 \\
Motivation (H6) & 1.76 & 1.25
\end{tabular}

calculated using the SPSS (statistical package for the social science) software.

Mean has been considered the most suitable method for the Likert-scale data because the target is to get the mean of the answers from all questions for each hypothesis [19].

Based on the data above, managers believe that strategic planning process is fine and the continuous improvement goals are in cooperated more than what team members think.

Moreover, the company hasn't adapted the change to match the new method of work.

Both managers and team members think that the correct measurements and performance indicators are used to measure the CI results continuously.

Both managers and team members think that the results are not sustained and the improvement results were very short-lived.

Managers believe they have received the required training on the continuous improvement subjects more than what team members did.

Both managers and team members think that there is no effective motivation system being used.

In conclusion, we can see that hypothesis $\mathrm{H} 1, \mathrm{H} 2, \mathrm{H} 5$, and $\mathrm{H} 6$ are verified taking into account the mean that were calculated from all variables determinations with values of 2.62 for managers and 2.33 for team members. Hypothesis $\mathrm{H} 3$ is acceptable for team members and not acceptable for managers.

\section{Discussions}

As previously mentioned, the proposed hypothesis model is partially verified taking into account the mean that were calculated from all variables determinations with values of 2.62 for managers and 2.33 for team members. Hypothesis $\mathrm{H} 4$ needs some improvements. Hypothesis $\mathrm{H} 3$ is verified in case of team members and needs some improvements in case of supervisory and managerial levels.

- Strategic planning process is adequate at the high level and continuous improvement goals are in cooperated, but the strategic goals aren't linked properly to the bottom level. Employees don't know how their work is going to affect the company's goals and vision. There is no proper link between the shop floor efforts and the strategic objectives to help people see not just their own improvements but how those improvements tie in to the bigger stream. People need a clear direction. They need to know where you're taking them 
[8]. To link strategic thinking to the shop floor, a leader has to learn how to lead at the gemba (the place where the work is done) [11]. Training leaders at the working place is also a part of change adoption process (hypothesis $\mathrm{H} 2$ ).

- Change management mean is low. The proper management approach is not being used; employees are being managed only by the achieved objectives. Managers are focusing on the results rather than the process and the method of accomplishing the goals. The company didn't train leaders at the gemba. There is no system to allow employees to share their own ideas for improving their own work and managers decide what should be done.

- Knowledge management is on the average mean and relativity low in case of team members. Employees haven't received the required training in order to manage the process with the new method. Managers received training but they haven't acted as mentors for the team members. Knowledge sharing to create a learning organization is necessary in continuous improvement environments. Training employees in problem solving is one of the most critical steps in achieving targets and removing obstacles. Most companies that fail to make real improvements and achieve good results have neglected training and coaching or haven't used the correct training behavior [1] [16]. Training and coaching are necessary parts of the process. Companies need to invest more in training and treat employees as valuable assets. Unfortunately, many companies are driven by short-term financial thinking and during recessions often cut costs and reduce wages. Their first thoughts are to suspend any training processes in order to reduce overhead costs [1] [8].

- CI performance measurements are on the average mean. Managers use the appropriate metrics to measure the outcomes and the performance of the process. Employees use metrics to measure their own work progress and report to managers.

- CI sustainability mean is low. Going back to the literature review we can figure out why many companies are suffering from sustainability issues and the improved results are very short-lived. Training must be carried out for every single employee and manager in the company. There is a strong relation between sustainability (hypothesis H5) and knowledge management (hypothesis $\mathrm{H} 3$ ).

- Motivation mean is low. Basically, employees think wages are low and there is no fair promotion system to upgrade positions based on performance. Furthermore, company uses the wrong motivation behavior. Instead of just using financial incentives and tie them to some metrics, morale motivators can reduce the use of financial incentives [26]. Many alternatives have been proven successful. This includes granting a certificate of appreciation to anyone who demonstrates good behaviors and good leadership capabilities or performs coaching and training. A company can also grant a certificate to anyone who passes a test with remarkable results [1]. Tests can be practical and involve real problem solving. If employees are practicing what they learn, their learning experiences will be increased through implementation. Both 
the organization and the employee receive benefits from this system. After coaching and certifying successful employees, those people will recognize the company's investment in them. These certificates can also be useful for their future careers. Using a certain promotion system is also a good motivator. Those who demonstrate good leadership will be promoted. Those who don't will attend more training cycles and have fewer people reporting to them [6]. They will not be promoted until they show good leadership capabilities. To succeed with your improvement projects, your people should believe in the process. They should believe they are implementing improvements so that their work can become easier and safer. They should not do it to get rewarded. They should be allowed to share their ideas through a highly self-motivating and cooperative system in order to improve their work. With a stable environment, the company's overall profitability will increase and allow more jobs for the labor force. People should understand this. The organization's culture and habits greatly affect people's behavior and teamwork.

- There are a lot of safety concerns in the working place. Apart of any motivational system that people need to feel secured in their work and that the company cares about their safety and health. For example, a clean, safe, and comfortable environment using $5 \mathrm{~S}$ tool lets laborers know that everyone in the company is committed to employee safety and satisfaction. These good attitudes permeate throughout the organization. Instead of just being things to accomplish, targets become ways to drive improvements, make processes safer and easier, and increase employee productivity.

- If leaders are practicing gemba walks (a part of the change adoption process) they will be able watch the working environments to see if anything negatively affects employee safety [9]. They should make sure operators are not performing unsafe acts, and they should monitor working environments for problems that prevent laborers from doing their jobs smoothly. This improves morale and satisfaction and is a part of any successful motivation system.

\section{Conclusions and Recommendations}

The objective of this research was to study the requirements of CI implementation. This research is limited to the manufacturing environments. It adds value to the manufacturing organizations and creates awareness about the transformation requirements in form of $\mathrm{CI}$ implementation.

The results show that continuous improvement is applicable in the manufacturing organizations in Egypt. Motivation, training and good planning are the most significant factors in the success of implementation. There is a strong relation between the applicability of the proposed hypothesis model and the success of CI implementation in terms of goals' accomplishment and sustainability of results.

Implementing $\mathrm{CI}$ initiatives in the Egyptian manufacturing industries are a 
challenged mission especially with the current economic situation which forces companies to cut costs and neglect training. Also culture adaptability is highly important and employees must practice the new behavior so improvement becomes a routine. Management needs to shift completely from command and control to empowerment, motivation, and support.

$5 \mathrm{~S}$ need to be a part of any continuous improvement process. A well-organized, clean, safe and healthy workplace improves employees' morale and satisfaction, helps organizations reduce wastes and improves quality.

\section{References}

[1] Ahmed, M.H. (2013) Lean Transformation Guidance: Why Organizations Fail to Achieve and Sustain Excellence through Lean Improvement. International Journal of Lean Thinking, 4, 31-40. http://thinkinglean.com/img/files/PAPER_4(2).pdf

[2] Angel, D.C. and Pritchard, C. (2008) Where "Six Sigma" Went Wrong. Transport Topics, 5.

[3] Byrne, A. (2012) The Lean Turnaround: How Business Leaders Use Lean Principles to Create Value and Transform Their Company. McGraw-Hill, New York.

[4] Liker, J.K. (2002) The Toyota Way: 14 Management Principles from the World's Greatest Manufacturer. McGraw-Hill, New York.

[5] McLean, R.S. and Antony, J. (2014) Why Continuous Improvement Initiatives Fail in Manufacturing Environments? A Systematic Review of the Evidence. International Journal of Productivity and Performance Management, 63, 370-376. https://doi.org/10.1108/IJPPM-07-2013-0124

[6] Liker, J.K. and Convis, G.L. (2012) The Toyota Way to Lean Leadership: Achieving and Sustaining Excellence through Leadership Development. McGraw-Hill, New York.

[7] Jaca, C., Viles, E., Mateo, R. and Santos, J. (2012) Components of Sustainable Improvement Systems: Theory and Practice. The TQM Journal, 24, 142-154. https://doi.org/10.1108/17542731211215080

[8] Soliman, M.H.A. (2016) Hoshin Kanri: How Toyota Creates a Culture of Continuous Improvement to Achieve Lean Goals. CreateSpace, South Carolina.

[9] Soliman, M.H.A. (2015) A New Routine for Culture Change. Industrial Management, 57, 25-30.

[10] Drucker, P.F. (1954) The Practice of Management. HarperCollins Publishers, New York.

[11] Liker, J.K. and Trachilis, G. (2015) Developing Lean Leaders at All Levels: A Practical Guide. Lean Leadership Institute Publications, Cambridge.

[12] Balle, M. and Balle, F. (2014) Lead with Respect: A Novel of Lean Practice. Lean Enterprise Institute, Cambridge.

[13] Balle, M. and Balle, F. (2010) Lean Manager: A Novel of Lean Transformation. Lean Enterprise Institute, Cambridge.

[14] Taylor, F.W. (1919) The Principles of Scientific Management. Harper \& Brothers, New York.

[15] Kaufman, J. (2012) The Personal MBA: Master the Art of Business. Portfolio Publishing, New York.

[16] Rother, M. (2009) The Toyota Kata: Managing People for Improvement. Adaptiveness and Superior Results. McGraw Hill, New York. 
[17] Quesada-Pineda, H.J. and Madrigal, J. (2013) Sustaining Continuous Improvement: A Longitudinal and Regional Study. International Journal of Engineering Business Management, 5, 43.

[18] Blaikie, N. (2003) Analyzing Quantitative Data. From Description to Explanation. Sage Publications, Thousand Oaks, 353. https://doi.org/10.4135/9781849208604

[19] Lissitz, R.W. and Green, S.B. (1975) Effect of the Number of Scale Points on Reliability: A Monte Carlo Approach. Journal of Applied Psychology, 60, 10-13. https://doi.org/10.1037/h0076268

[20] Singh, R.M. and Gupta, M. (2014) Knowledge Management in Teams: Empirical Integration and Development of a Scale. Journal of Knowledge Management, 18, 777-794. https://doi.org/10.1108/JKM-11-2013-0450

[21] Manolopoulos, D. (2007) An Evaluation of Employee Motivation in the Extended Public Sector in Greece. Employee Relations, 30, 63-85. https://doi.org/10.1108/01425450810835428

[22] Herzberg, F. (1968/2003) One More Time: How Do You Motivate Employees? Harvard Business Review, 46, 87-96.

[23] Jurgensen, C.E. (1978) Job Preferences (What Makes a Job Good or Bad?). Journal of Applied Psychology, 63, 267-276. https://doi.org/10.1037/0021-9010.63.3.267

[24] Tharenou, P. (1993) A Test of Reciprocal Causality for Absenteeism. Journal of Organizational Behavior, 14, 269-287. https://doi.org/10.1002/job.4030140306

[25] Nunnally, J. (1978) Psychometric Theory. McGraw-Hill, New York.

[26] Osterloh, M., Frey, B. and Frost, J. (2002) The Dynamics of Motivation of New Organizational Forms. International Journal of the Economics and Business, 9, 61-77. https://doi.org/10.1080/13571510110102976

Submit or recommend next manuscript to SCIRP and we will provide best service for you:

Accepting pre-submission inquiries through Email, Facebook, LinkedIn, Twitter, etc. A wide selection of journals (inclusive of 9 subjects, more than 200 journals) Providing 24-hour high-quality service

User-friendly online submission system Fair and swift peer-review system Efficient typesetting and proofreading procedure Display of the result of downloads and visits, as well as the number of cited articles Maximum dissemination of your research work

Submit your manuscript at: http://papersubmission.scirp.org/

Or contact ajibm@scirp.org 